\title{
Factors influencing local competition intensity
}

\author{
Branislav Zagorsek ${ }^{*}$ \\ University of Economics in Bratislava, Department of Management, 85235 Bratislava, Slovak \\ republic
}

\begin{abstract}
This paper investigates the factors influencing the intensity of local competition. The research results may be of interest to companies if deciding whether to enter a market or by defining a new market. Understanding which factors impact the competition the most also helps to address these factors when dealing with competitors and other subjects. The studied factors were selected based on Porter's model of five competitive forces. The data were obtained from the World Economic Forum database. To analyze the data, the statistics software PSPP and the programming language Python with statistical package Statsmodels were used. The results were considered to be statistically significant if they were on significance level $\mathrm{p} \leq 0.05$. The finding is that higher competition intensity is positively influenced by the number of local suppliers, foreign competition, intellectual property protection, and negatively by spending on research and development. This research may serve as a guideline for companies. If a company is entering a new market, the results presented in this paper may help to assess the intensity level of local competition by identifying the most influential factors.
\end{abstract}

\section{Introduction}

The globalization of the economy is represented by foreign trade, the flow of capital, and the spread of technologies, along with market integration [1]. It affects companies on the national as well as on the local scale by intensifying competition. Among other issues, local businesses do not only compete with their direct neighbors but also with businesses on the other end of the world. Information technologies are another factor that contributes to this intensification of competition. Thanks to the widespread and easily accessible information the consumers are more informed about the products and the product providers. It is essential to understand these mechanisms and factors influencing competitiveness so that the companies can adjust their business models and activities accordingly.

\footnotetext{
*branislav.zagorsek@euba.sk
} 
In this paper, the factors that impact the intensity of local competition were examined. The objective is to identify factors that are influencing this intensity. We want to find out whether there are factors that companies can focus on to deal with competition more effectively.

\section{Literature review}

Alexander [2] by showing how territorial location can shape the sustainability of the product, depending on whether adequate waste processing facilities are available and how related practices are regulated, created a basis for the argument that the presence of local suppliers might influence the business. Ma [3] argues that competitive advantage is not defined clearly enough and that competitive advantage and performance are rather two different constructs. Dollinger [4] wrote that sustainable competitive advantage arises when the enterprise creates and captures value and protects it against erosion by competitors. Dollinger also describes the four conditions affecting higher competition intensity. These conditions include numerous equally balanced competitors, slow growth in the industry, high fixed costs and a commoditytype product. Porter [5] has identified five competitive forces to describe the competition and subsequently adjust the strategy. These five competitive forces include supplier power, buyer power; the threat of substitution; the threat of new entry and competitive rivalry. Malecki and Oinas [6] claim that the level of innovativeness and competitiveness of firms everywhere depends not only on the degree to which they are embedded within local networks of suppliers but also on the presence of links to external markets. Jankelova et al. [7] claim that by optimizing the organizational structure, the company could overcome economic insecurity more easily during the times of the crisis. To keep the company competitive, Rocha and Abreu [8] believe it is important to create conditions for flexible governance regimes. This would help to reduce the power of the large retailers in setting prices and production standards across the value chain, immensely reducing the financial pressures on producers to continuously cut costs, and creating the possibility to invest in a technological and organizational upgrade. Hamel [9] found that a firm with no ambition beyond the investment avoidance and substitution of its partner's competitiveness for its own lack of competitiveness may be perfectly content not to learn from its partner what is likely to undermine the competitiveness and independence. Krugman [10] claims that the company is not competitive unless it can maintain its position on the market, so if it does not increase its performance, it will have to leave the market. Collins and Troilo [11] made an argument for public-private partnerships for innovation as these may increase the competitiveness of small and medium-sized companies. The positive relation between competition and higher economic growth or economic progress was argued by Dutz and Hayri [12] and Porter [13]. Meanwhile, Ireland and Webb [14] and Dyer and Singh [15] associated spending on research and development with a possible competitive advantage. Dosi et al.[16] argue that market shares at the country level are mainly influenced by technology, while the cost advantage or disadvantage does not have a significant impact. Siriphattrasophon [17] claims that businesses that have more international activities are more competitive than others. Bharati and Chaudhury [18] claim that although small and medium-sized enterprises are not generally technology-demanding, they are the innovators themselves as they produce 13 to 14 times more patents per employee per year than large enterprises. Slavik and 
Zagorsek [19] claim that in order for the business model to be set as the entrepreneurs want, it must be matched with strategic factors. If the company has some idea of its competitive behavior, it must have a strategy that will allow to exercise it. The challenge of competitiveness (Gibb) [20] is one of finding new ways of converting the learning skills needs for SMEs and the stakeholders into the training demands of the future. According to Quack et al. [21], competences and capabilities of a company can influence its ability to adapt to changing business environment and pressure from global competition with consequent effects for their own economic performance, the performance of their sector, and that of their home nation-state.

\section{Methods and Objectives}

This paper aims to identify the factors that influence the intensity of local competition the most. Analyzed data were obtained from the World Economic Forum database. The analyzed variables were selected on the basis of Porter's five competitive forces model [5], which identifies five groups of factors affecting the competition: supplier power, buyer power; the threat of substitution; the threat of new entry and competitive rivalry. Based on this model, a search for variables in the database that represent individual groups of factors was conducted. The Global Competitiveness Index dataset that was used contains data for 137 countries of the world, where each county was presented by one data point per variable representing the mean value. The dataset used in this research was acquired between 2017-2018. In general, the survey data could have values from 1 to 7 , with 1 being the lowest and 7 being the highest outcome. The variables number of days and the number of tasks required before starting a business are not on a scale, but they are the real values in each country. Questions and variables are described to greater detail in the Global Competitiveness Report 2017-2018[22]. The database was imported into Python and analyzed using the Numpy, Pandas, Matplotlib, and Statsmodels packages. The data were subjected to graphical analysis and inductive statistics. The package used for linear regression is further described by Seabold and Perktold [23]. When analyzing the data, the methods of descriptive statistics and graphical analysis were used to describe the data. Consequently, multiple linear regression, ANOVA, Durbin-Watson test and JarqueBera test were used. The method of linear regression was utilized as a tool for comparing the effects of individual exogenous variables on an endogenous variable. Statistically significant were considered results with $\mathrm{p} \leq 0.05$.

\section{Results}

Our research focuses on the intensity of local competition. In order to account for the impact of competition from abroad, the intensity of foreign competition was used as the control variable. Indicators of barriers to market entry (number of days to start a business; the number of procedures to start a business) and production process sophistication represent the threat of new entry and the threat of substitution. These factors make it more difficult for potential competitors to enter the market. They represent barriers that must be overcome by new businesses at a time of uncertainty before their products can be sold or barriers that must be surpassed to acquire customers. Supplier power (local supplier quality; local supplier quantity) and buyer 
power (buyer sophistication; domestic market size) indicators represent the negotiating power based on the quantity and quality or sophistication of these subjects. The individual variables are described in Table 1.

Table 1. Variable description

\begin{tabular}{lllllll} 
Variable & $\mathrm{N}$ & Avg & St. d. & Med & Min & Max \\
\hline Intensity of local competition & 137 & 5.0 & 0.6 & 5.1 & 2.8 & 6.2 \\
Intensity of foreign competition & 137 & 4.5 & 0.8 & 4.5 & 2.6 & 6.4 \\
Intellectual property protection & 137 & 4.3 & 1.0 & 4.1 & 2.0 & 6.6 \\
Number of days to start a business & 137 & 19.4 & 26.2 & 11 & 0.5 & 230 \\
Number of procedures to start a & 137 & 6.8 & 3.1 & 6 & 1 & 20 \\
business & & & & & & \\
Buyer sophistication & 137 & 3.5 & 0.8 & 3.4 & 1.8 & 5.3 \\
Degree of customer orientation & 137 & 4.7 & 0.7 & 4.6 & 2.4 & 6.2 \\
Domestic market size & 137 & 3.7 & 1.2 & 3.7 & 1 & 7 \\
Ease of access to loans & 137 & 3.9 & 0.8 & 3.9 & 1.5 & 5.7 \\
Quality of overall infrastructure & 137 & 4.1 & 1.1 & 4.1 & 1.5 & 6.7 \\
Production process sophistication & 137 & 4.0 & 1.1 & 3.8 & 2.0 & 6.5 \\
Company spending on R\&D & 137 & 3.6 & 0.9 & 3.3 & 1.9 & 6.1 \\
Local supplier quality & 137 & 4.4 & 0.7 & 4.4 & 2.4 & 6.3 \\
Local supplier quantity & 137 & 4.5 & 0.6 & 4.6 & 2.4 & 6.2 \\
\hline
\end{tabular}

To get the final model, the non-significant variables were removed with respect to adjusted R-squared with the goal of creating a relevant model of the intensity of local competition. The relevant model means that the model explains as much of local competition intensity as possible and consists of only or almost only significant variables. After adjustments, the model displayed in Table 2 emerged. By eliminating non-significant variables, the model improved in the goodness of fit. The model of the intensity of local competition with adjusted $\mathrm{R}^{2}=0.746$ consists of the intensity of foreign competition, local supplier quantity, spending on research and development, intellectual property protection, and degree of customer orientation. In this model, the quantity of local suppliers influenced the intensity of local competition the most, followed by the negative impact of company spending on research and development and the positive impact of intensity of foreign competition, the degree of customer orientation and intellectual property protection.

Unlike, in theory, the research found that a larger number of suppliers is associated with higher competition intensity. This may be caused by the nature of the local market where the reason for a large number of suppliers might be given by a number of competing companies whom the suppliers provide the products and so the competition is more intense. This research also found that investing more in research and development is associated with the lower intensity of local competition. As a part of natural explanation research and development is considered to be a potential source of competitive advantage that may create barriers for competitors and thus reduce the intensity of competition. The expected result that the higher intensity of foreign competition will lead to higher intensity of local competition can be explained by the 
fact that local businesses compete not only with their direct neighbors but also with foreign companies what makes them take into account more subjects making the situation more complex and so the competition more intense.

Table 2. Regression model of the intensity of local competition

\begin{tabular}{lccc}
\hline & coefficient & $\begin{array}{c}\text { standard } \\
\text { error }\end{array}$ & $\mathrm{p}$ \\
\hline Intensity of foreign competition & 0.157 & 0.048 & $0.001^{* *}$ \\
Intellectual property protection & 0.134 & 0.058 & $0.023^{*}$ \\
Degree of customer orientation & 0.148 & 0.068 & $0.032^{*}$ \\
Company spending on R\&D & -0.161 & 0.061 & $0.009^{* *}$ \\
Local supplier quantity & 0.639 & 0.061 & $0.000^{* *}$ \\
$\mathrm{R}^{2}$ & 0.755 & & \\
Adjusted $\mathrm{R}^{2}$ & 0.746 & & \\
$\mathrm{~F}(5,131)$ & $80.92 * *$ & & \\
Durbin-Watson test & 1.840 & & \\
Jarque-Bera test & 0.226 & & \\
\hline$* \mathrm{p} \leq 0.05 * * \mathrm{p} \leq 0.01$ & & &
\end{tabular}

A higher level of intellectual property protection is associated with a higher intensity of local competition. A possible explanation is that the need for proper protection itself arises in a situation that is more likely to be associated with intense competition. In other words, if the protection of the intellectual property is not needed, it is likely that the intensity of competition is not high, because the market is large enough for companies not to worry about their survival. In turn, the positive effect of the degree of customer orientation on the intensity of local competition may be explained as companies that care more for their customers and consider more variables of customer satisfaction. This makes the competition more intense, as competing companies also have to take into account more information.

\section{Discussion}

The intensity of local competition is a condition with a great impact on business success. This can be seen either as an a priori argument supported by probability, the argument from biology or argument supported by economic research. If there are more subjects selling the same product, there are more options for the buyer from whom to buy the product. This lessens the probability of buying it from one specific company by applying basic probability calculation. If an experiment must result in one of the $n$ outcomes and the outcomes are equally likely, the probability of an outcome is $100 / \mathrm{n}$ percent, and so the more companies, the less likely is the success. In biology research, where competition between and within species (Hardin)[24] is studied, the basic principle of competition can be derived as there cannot be coexisting complete competitors. That means increased competition results in increased default. However, economic research further suggests that competition may lead to higher economic growth or progress $[12,13]$. Therefore, the higher intensity of local competition can be perceived as a threat for emerging companies and companies with prominent weaknesses and as an opportunity for companies with a competitive advantage. This 
impact of intensity of competitiveness is the reason for the importance of understanding the competitive environment for companies operating in a market or entering one. The results presented in this paper can be interpreted in the following ways. The most interesting findings reveal the nature of the intensity of local competition and factors influencing it. By far, the biggest impact among the studied variables was the impact of local suppliers' quantity. This can be the result of causation or can be used as an indicator. The larger number of suppliers results in stronger negotiating power of buyers. These better conditions may lead to increased incentives to enter the market by other companies. The increased interest leads to a higher number of competitors and so to more intense competition. Other interpretation is from the perspective of the observer using the number of local suppliers as an indicator of competition. In this case, the higher number of companies indicates that there must be a higher number of buyers and so a more intense competition among them. At first sight, the most surprising result is the negative impact of research and development. In this case, the causation is not clear. It could be expected that companies are spending more on research and development because they perceive higher competition intensity. However, the results indicate that spending on research and development might be an important competitive tool creating a possible competitive advantage, as suggested by literature [14,15]. Companies with higher spending on research and development perceive local competition as less intense. This might be the outcome of the competitive advantage gained by the R\&D. As the results show in the time of globalisation, the impact of foreign competition is also significant and should not be ignored. Companies entering a local market that might seem vacant have to reconsider this first sight perception and a further look at whether there is a foreign competition that might interfere with their operations. The degree of customer orientation seems to have a straightforward interpretation. The more attention is drawn to customer orientation in the market the more intensity of local competition there is. The explanation would be that if there are more competitors and some of them start to differentiate themselves by intensifying customer orientation, other competitors are also forced to increase their customer orientation. This leads to a higher level of competition. Intellectual property protection indicates the intensity of local competition. If companies compete and the competition arises, the need for intellectual property rights protection also rises, and companies may pressure the government to do so.

\section{Conclusion}

This paper investigated the factors influencing the intensity of local competition. Examined factors were selected in accordance with Porter's model of the five competitive forces framework, while the data were obtained from the World Economic Forum database. The finding presented in this paper pointed out the factors affecting the most the intensity of local competition. The finding is that a higher number of local suppliers affected the higher intensity of local competition. Furthermore, the intensity of local competition was impacted positively by foreign competition, intellectual property protection, and negatively by spending on research and development. This research may serve as a guideline for companies. If companies are entering a new market, it may help to assess the intensity of local competition by identifying the most influential factors. Furthermore, businesses can use the number of local suppliers and intellectual property protection as indicators of competition 
intensity. They can also fight the perceived intensity of local competition by investing in research and development.

The limitations of this study are as follow. There is a possibility of generalization of the study as there might be more meaningful influences on an individual basis, that did not show in statistical analysis. There is a possibility of hidden variables that were not considered in the model. The limited control over data collection is given by the use of World Economic Forum databases.

Additionally, an original value was added by this paper with a different point of view. The data used are relevant data selected from a database usually used in macroeconomics. This allowed us to study a problem from a different perspective, which is a valuable scientific approach, observing one phenomenon using different research channels. In future research, it should be considered worthwhile to understand further the mechanisms of factors influencing the intensity of local competition identified in this paper.

\section{Acknowledgment}

This paper is a part of VEGA n.1/0017/20.

\section{References}

1. G. Shangquan, Economic globalization: trends, risks and risk prevention. Economic \& Social Affairs, CDP Background Paper 1, (2000)

2. R. Alexander, Sustainability in global production networks-Introducing the notion of extended supplier networks. Competition \& Change 22, 255-273. (2018)

3. H. Ma, Competitive advantage and firm performance. Competitiveness Review: An International Business Journal 10, 15-32. (2000)

4. M.J. Dollinger, Entrepreneurship: Strategies and resources. (Marsh Publications, 2008)

5. M.E. Porter, The five competitive forces that shape strategy. Harvard business review $\mathbf{8 6}, 78-93$ (2008)

6. E.J. Malecki, P. Oinas, Making connections: technological learning and regional economic change. (Ashgate Publishing Company, 1999)

7. N. Jankelova, A. Jankurova, M. Benova, Z. Skorkova, Security of the business organizations as a result of the economic crisis. Entrepreneurship and Sustainability Issues 5, 659-671 (2018)

8. R. Rocha, M. Abreu, Emerging strategies and flexible forms of governance: The dynamics of role exchange in local value chains. Competition \& Change 22, 363$382(2018)$

9. G. Hamel, Competition for Competence and Inter-Partner Learning Within International Strategic Alliances. Strategic Management Journal 12, 83-103 (1991)

10. P. Krugman, Competitiveness: A Dangerous Obsession. Foreign Affairs 73, 28 44 (1994)

11. M.J. Collins, M.L. Troilo, National factor effects on firm competitiveness and innovation. Competitiveness Review 25, 392-409 (2015)

12. M.A. Dutz, A. Hayri, Does more intense competition lead to higher growth? The World Bank (1999) 
13. M.E. Porter, The Adam Smith address: location, clusters, and the "new" microeconomics of competition. Business Economics 33, 7-13 (1998)

14. D.R. Ireland, J.W. Webb, Strategic entrepreneurship: Creating competitive advantage through streams of innovation. Business horizons 50, 49-59 (2007)

15. J.H. Dyer, H. Singh, The relational view: Cooperative strategy and sources of interorganizational competitive advantage. Academy of management review 23, 660-679 (1998)

16. G. Dosi, M. Grazzi, D. Moschella, Technology and costs in international competitiveness: from countries and sectors to firms. Research Policy 44, 1795$1814(2015)$

17. S. Siriphattrasophon, Multi-level factors affecting firm competitiveness in ASEAN region of small and medium enterprises of Thailand. Kasetsart Journal of Social Sciences (2017)

18. P. Bharati, A. Chaudhury, SMEs and competitiveness: The role of information systems (2009)

19. S. Slavik, B. Zagorsek, How can strategy influence the internal nature of business model? Journal of applied economic sciences 12, 1080-1090 (2017)

20. A.A. Gibb, Small firms' training and competitiveness. Building upon the small business as a learning organization. International small business journal 15, 1329 (1997)

21. S. Quack, G. Morgan, R. Whitley, National capitalisms, global competition, and economic performance. (John Benjamins Publishing, 2000)

22. World Economic Forum, The Global Competitiveness Index dataset 2007-2017, available at: www3.weforum.org/docs/GCR2017-2018/GCI_Dataset_20072017.xlsx (2018)

23. S. Seabold, J. Perktold, Statsmodels: Econometric and statistical modeling with python. Proceedings of the 9th Python in Science Conference 57, 61 (Austin, SciPy society, 2010).

24. G. Hardin, The competitive exclusion principle. Science 131, 3409, 1292-1297 (1960) 